\title{
COMPARAÇÃO QUALITATIVA ENTRE 0 PROGRAMA BRASIELIRO DE ETIQUETAGEM EM EDIFICAÇÕES E $O$ SISTEMA DE CERTIFICAÇÃO ENERGÉTICÁ DOS EDIFICÍOS DE PORTUGAL: PROPOSTAS DE MELHORIAS NA REGULAMENTAÇÃO BRASILEIRA
}

\author{
Jaime Francisco de Sousa Resende (UFSJ); \\ Andrea Lucia Teixeira Charbel, Dra. (UFSJ); \\ Teresa Cristina Bessa Nogueira Assunção, Dra. (UFSJ)
}

As edificações representam uma importante parcela no consumo mundial de energia, e diante disso, o setor tem chamado a atenção dos governos, que passaram a adotar políticas para reduzir o gasto energético. As Certificações de Eficiência Energética em Edificações (CEEE) destacam-se como uma das possíveis soluções para alcançar este objetivo e são empregadas em diversos países do mundo.

De acordo com o Balanço Energético Nacional (BEN), o consumo de energia elétrica nos últimos dez anos (período 2007 - 2016) teve um aumento substancial de $26 \%$, enquanto a produção aumentou $30 \%$ no mesmo período (MINISTÉRIO DE MINAS E ENERGIA, 2017).

Uma redução de $30 \%$ no consumo de energia elétrica é estimada em edificações que efetuarem reformas que contemplem os conceitos de eficiência energética, e em até $50 \%$ para os novos edifícios que considerarem alternativas eficientemente energéticas desde a fase de projeto (PROCEL INFO, 2017).

A União Europeia apresenta avançados programas de avaliação energética de edifícios, sendo referência e modelo para diversos outros regulamentos no mundo. O Sistema de Certificação Energética dos Edifícios (SCE) de Portugal é considerado um caso de sucesso, refletido no número expressivo de cerca de 1,4 milhão de certificados energéticos expedidos (ADENE, 2018). O Programa Brasileiro de Etiquetagem em Edificações (PBE Edifica), que teve seus primeiros documentos lançados em 2009, ainda não se encontra consolidado no cenário brasileiro, contando com menos de 5 mil etiquetas emitidas (INMETRO, 2018).

Com o objetivo de propor melhorias para a regulamentação brasileira, foi realizada uma pesquisa da situação mundial das CEEE e sínteses regulamentares e estruturais do PBE Edifica e do SCE, elaborada uma comparação qualitativa entre ambos programas de etiquetagem, sendo destacados pontos positivos presentes na regulamentação portuguesa, que podem servir de exemplo para adaptação do PBE Edifica.

Foram realizadas as seguintes propostas: modificação do processo de emissão da etiqueta; avaliação e distinção de edifícios novos e existentes; fixação de valores e classes energéticas de referência; estabelecimento da etiquetagem compulsória; criação de incentivos para etiquetagem; criação de uma classe energética superior; e disponibilização de informações na etiqueta como o consumo avaliado em relação ao valor de referência, informações sobre contribuição de energias renováveis e emissões de CO2 e propostas de melhorias para a edificação avaliada.

\section{REFERÊNCIAS}

MINISTÉRIODEMINASEENERGIA. Balanço Energético Nacional - Ano Base 2016. Brasília, DF, 2017.

PROCEL INFO.PROCELEDIFICA -Eficiência Energética nas Edificações. Disponível em: <http://www.procelinfo. com.br/>. Acesso em 16 de março de 2017.

ADENE-AgênciaparaEnergia.Certificados Energéticos emitidos por tipo de edifício. Disponível em: <http://www. adene.pt/indicador/certificados-energeticosemitidos-por-tipo-de-edificio>. Acesso em 09 de janeiro de 2018.

INMETRO - INSTITUTO NACIONAL DE METROLOGIA, QUALIDADE E TECNOLOGIA. Tabelas de consumo/eficiência Energética - Edificações. Disponível em:<http://www.inmetro.gov.br/consumidor/pbe/edificacoes. asp >. Acesso em 09 de janeiro de 2018. 